\title{
INFORMATION AND DEMOCRACY
}

\section{Fake news as an emotional weapon}

\author{
Matthew Loveless
}

\section{Introduction}

In the field of Political Science, the role of information - whether through education, exposure, content availability - has been taken, normatively, as a linchpin of a democratic society (Dahl 1989). A quote widely, if erroneously, attributed to Thomas Jefferson is often used to underscore this important relationship, "An educated citizenry is a vital requisite for our survival as a free people." ${ }^{1}$ This is an intuitive and widely shared notion within Political Science, Sociology, Economics, and Psychology - as well as in popular culture. It makes intuitive sense that an individual or collection of individuals are better able to make appropriate decisions for themselves by understanding what is happening around them. In the field of politics, having both a sense of the ideological landscape and the positions of parties and their policies can only serve to improve the quality of democratic governance. Better and more information produces better individual and, in turn, collective decisions.

Yet, the evidence does not appear to bear this out. In the late 1950s, a team at the University of Michigan - Campbell, Converse, Miller, and Stokes - set out to survey the American public and to assess their political attitudes, choices, and behaviours. The resultant publication, The American Voter (1960), showed that Americans' political attitudes appeared to originate from such profoundly unstructured political beliefs that the authors reported a stunning lack of sophistication and rationality. Key's book, Public Opinion and American Democracy, the following year (1961) as well as Butler and Stokes' book, Political Change in Britain (1969) did little to challenge these findings, showing that, in the latter case, Americans were not unique in such under-informed political states.

Political Science has taken one of two approaches to deal with this 'discovery'. One approach has been to either say that democratic outcomes appear - at least in the aggregate - 'rational' (Page and Shapiro 1992) or to call individual political 
choices 'reasoned' to the extent that individuals must have some process through which information is both gathered and (more importantly) incorporated to make decisions (Lupia and McCubbins 1998). Others searched for answers at the individual level. Zaller (1992) was among the first and most influential scholars to argue that how individuals process information explains how they formulate their opinion but that most of the information used to do so was heuristically driven; that is, more or less directly from elites and media. In other words, internal processes and external cues compensate for low concrete and specific political knowledge in the same way that knowing how to do multiplication saves you from having to memorise all possible combinations of any two numbers (Lodge and McGraw 1995). Yet, and still, Americans and Europeans continue to show low levels of both political knowledge and sophisticated processing skills (Sniderman, Brody, and Tetlock 1991; Lupia, McCubbins, and Popkin 2000).

In terms of information and democracy, while attention is scarce and the ability to process information is low, the sources of information have increased. The exponential growth in the availability of information stresses the need for individuals to develop some method for sorting the growing torrent of information. In addition to the ability of legacy media to broadcast to a near comprehensive audience over the past 40 years, a (slim) majority of the world's population has had at least some access to the largest repository of collected knowledge: the Internet. ${ }^{2}$ Yet, over precisely the same period, the once solid footing of post-war democratic institutions has begun to deteriorate. In other words, greater availability to greater absolute amounts of information does not appear to resolve the information and democracy dilemma. In fact, it appears to have made it worse.

Fake news is a key debate in this dilemma. Fake news is an emotional weapon which refers not to discrete instances or stories, but rather to the strategic effort to cloud current debates with the aim of manipulating audience's feelings to undercut any potential for collective (political) action. As increasingly recognised by the mainstream literature on political sophistication and cognition, such emotive appeals often overwhelm individuals' attempts to reason with political topics (Druckman 2012; Edelson et al. 2017; Flynn, Nyhan, and Reifler 2017; Karp, Nai, and Norris, 2018; Prior, Sood, and Khanna, 2015; Redlawsk 2002; Suhay et al. 2015). Fake news is weaponised by appealing directly to people's emotions rather than their intellect. The driving force for using and supporting fake news is to scramble and divide public opinion in order to benefit from the resultant chaos, whether financially or politically.

\section{How fake news disrupts democracy}

In addition to greater availability of information, the Internet has opened up greater opportunities for misinformation. One of its most common forms is fake news. The term 'fake news' is both specific and broad. Fake news is not propaganda or 'spin' in which a group, such as a political party, might try to reframe events so 
that the group is seen in a more positive light (Uscinski 2019). Fake news is similar to a hoax, in that it is a deliberately fabricated falsehood made to masquerade as truth (ibid.). Although presented as being factually accurate, fake news has little or no basis in fact (or is a dissembled fusion of bits and pieces of factual things). Its distinguishing feature is that fake news is strategically deployed with an ostensive financial incentive or damaging purpose (Walker 2018). As such, it is a weapon.

The efficacy of this weapon corresponds with the transition of citizens from passive consumers to active selectors of political cues (Prior 2007). This self-selecting exposure depends on previous patterns and goes by names that vary by discipline: selective exposure, informational congeniality, pro-attitudinal information search, or confirmation bias, inter alia. Simply, in a sea of information, consumers cling to what they know. In terms of searching for information, this process has led to the silo-ification of consumers, informational bubbles, filter bubbles, echo chambers in which individuals' understandings of the world are decreasingly exposed to counter-narratives, critiques, and outright challenges.

Information silo-ification originated with the idea that the information systems could be constrained from freely communicating with other information systems, i.e. operate in a silo. Applied to individuals, information silo-ification refers to a situation in which that person is unable to freely communicate with - or be exposed to - alternative information sources (Garrett 2017). Silo-ification is commonly the result of Internet search filters and histories that increasingly narrow online searches, in turn developing decreasingly varied algorithmic selectivity and thus lower exposure to other (i.e. unlike) information sources. The individual is thus increasingly constrained to an informational environment in which one's own beliefs about the world are amplified and reinforced in a closed communication system. While the various steps of the process overlap, they refer to the decrease in alternative information and the increase in the repetition and fortification of one's own worldview. In this environment, fake news finds a fertile field of targets.

Polls show that conspiracy theories and fake news are popular everywhere, including Europe, in which popular perceptions of the extent of both in the public sphere are similar if not greater than in the US (Uscinski 2018). At the same time, public attention to fake news and misinformation has grown, because of recent controversial and divisive events such as Brexit and the 2016 US presidential election (Allcott and Gentzkow 2017; Karp, Nai, and Norris 2018; Flynn, Nyhan, and Reifler 2017; Lazer et al. 2018; Lewandowsky, Ullrich, and Cook 2017). Yet, the crucial issue is less about the consumption but rather the strategic deployment of fake news as a weapon to shape politics. That is, fake news offers a means for some to circumvent a reality which disallows others' preferred outcome. For democratic politics, this is deeply problematic.

One of the core tenets of early Internet evangelism was the democratisation of voices (Dahlgren 2000; Shirky 2011; Valenzuela, Park, and Kee 2009; Ward, Gibson, and Lusoli 2003; Weber, Loumakis, and Bergman 2003; Zhang et al. 2010; Gil de Zúñiga, Jung, and Valenzuela 2012). However, this has had the unintended consequence of undermining the role of expertise. Information and 
data are, on their own, not equal to knowledge. There must be some process by which information and data become useable, and that process is the competent application of knowledge (i.e. expertise). The equalisation of all voices - the deterioration of expertise - does not naturally transform into a free market of ideas in which ideas compete for constituents. Not all ideas have equal standing. There must be a justifiable process for distinguishing between ideas that are allowed into the market and those that must be discounted and possibly excluded. The Internet has introduced previously unforeseen issues that have created a difficult landscape on which to fight fake news. Thus, the use of fake news finds a welcome home on the Internet as many of the traditional definitions associated with media have melted away: Who is a 'reporter'? Who is an 'expert'? What constitutes 'news'?

This atrophy of expertise corresponds to the rise of emotional politics, in which facts are allowed to be replaced by what one believes or feels to be true. There is a growing body of scholarly work that shows that knowledge - i.e. information about the world - is simply less important in determining individual choices than what individuals believe it to be (Druckman, Peterson, and Slothuus 2013; Hart and Nisbet 2012; Suhay et al. 2015; Druckman 2012; Kunda 1990; Kahan 2016; Lodge and Taber 2000; Redlawsk 2002). ${ }^{3}$ As the distance between political sophistication and political behaviour grows, that is, as people rely less on key and reliable information sources, they tend to base political decision-making on feelings and emotions (Lau, Andersen, and Redlawsk 2008; Luskin 1987; Sniderman, Brody, and Tetlock 1991; Taber and Lodge 2006). Simply, facts have become either secondary, debatable, or ultimately inconsequential to what one believes - or feels to be true. The loss of expertise and concomitant rise in preferring feelings to facts converge to create an environment in which fake news - as a strategic, emotional weapon - can thrive.

The implications of competing subjective realities as the basis for orienting oneself to the world are not hard to imagine. At the broadest level, it has been observed that greater numbers of citizens are acting against their own (observable) self-interest (Achen and Bartels 2016). Yet the deterioration of the ability for - small ' $t$ ' - truth to outweigh fiction fits a broader pattern that has been more recently formalised. Kavanagh and Rich (2018) call this phenomenon "truth decay". "From the Introduction to their book, they define it as a set of four connected and observable trends (2018: 3):

1. Increasing disagreement about facts and analytical interpretations of facts and data;

2. A blurring of the line between opinion and fact;

3. The increasing relative volume, and resulting influence, of opinion and personal experience over facts;

4. Declining trust in formerly respected sources of factual information.

Each on its own represents an independent challenge to distinguishing fact from fiction (or, opinion). However, as the authors point out, it is their synergistic 
convergence and strategic deployment, with increasingly sophisticated means such as message micro-targeting in social media, that has allowed for truth decay to grow rather than be contained.

The message from Kavanagh and Rich is that, while the contest between facts, opinion, and outright fiction has a long history (in their examination, in the US, but with clear application to Europe), it is the ability to outright control information flows and target the most susceptible that distinguishes the present from previous periods. That is, fictions and opinions are used as weapons to actively challenge what may seem to be demonstrable reality. And the means most appropriate, and what Kavanagh and Rich (ibid.) cite as drivers in the US, are employing means to manipulate individuals' psychologies via cognitive processing and built-in biases (e.g. which concepts, beliefs, and rules one applies to the evaluation, Kunda 1990; Sniderman 2000) as well as their emotional profiles (i.e. galvanising individual partisanship as well as cultivating negative partisanship) in the context of greater political polarisation.

The US is not alone. The rise of regional autonomy movements, Brexit, the rise of soft dictators in Eastern Europe, the migration question, the rise of both extreme and new parties, and terrorism represent only the most visible contemporary and concurrent events that directly challenge democratic states' abilities to respond. Thus, the most insidious effect of fake news' impact on the weak bond between information and democracy is the negative downstream effect it has had on democratic political culture by de-legitimising democratic institutions.

In the context of European democratic systems, and specific to the relationship between information and democracy, the limitlessness of digital platforms in the age of fake news/disinformation is a substantive problem. At minimum, it has created more opportunities for financially or ideologically motivated producers. Non-state political actors have the capacity not only to initiate cross-national links with like-minded parties but also to roll out coordinated public 'information' campaigns.

As mentioned earlier in the chapter, early Internet evangelists promised that by making social media widely available - that is, democratic, inasmuch as anyone can participate equally - we would not only strengthen our own democratic cultures but spread democratic inspiration to non-democratic countries (Dahlgren 2000; Shirky 2011; Valenzuela, Park, and Kee 2009; Ward, Gibson, and Lusoli 2003; Weber, Loumakis, and Bergman 2003; Zhang et al. 2010; Gil de Zúñiga, Jung, and Valenzuela 2012). More Internet, more social media, more democracy. However, over the past two decades, the only coherent social media effect to have been clearly identified is the silo-ification of information provision and the construction of echo chambers. This has led, instead of in the direction of more democracy, towards greater polarisation and separation.

A broader perspective suggests that the loss of expertise and the ability to speak with one another about the same set of facts is the results of the strategic deployment of the emotional weapon of fake news. Namely, rather than simply individuals' information silo-ification, we can see a torrent of half-truths, conspiracy 
theory, and misdirection in the news-sphere. The strategic goal is to drown any signal with an over-abundance of noise. ${ }^{5}$ In this way, the inundation of the public space with every variety of specious 'news' results in an emotional toll on the consumer who begins to not only question every story - true or fake - but also considers resigning from the increasingly difficult task of differentiating real from fake news altogether. ${ }^{6}$ At the individual level, exposure to and acceptance of misinformation, fake news, and conspiracy theories correspond with individual negative epistemic motives (e.g. seeing self-reinforcing patterns where none exist) or negative existential motives (e.g. alienation, Douglas et al. 2019; Clarke 2007); a deficiency in the ability to reason clearly or apply logic (Ståhl and van Prooijen 2018); a propensity toward delusional (Freeman 2007) or dogmatic thinking (Berinsky 2012); or even experiences of hallucinations (Dagnall et al. 2015). ${ }^{7}$ Thus, fake news is emotional in the sense that it has very real, negative individual psychological correlates, creating individual disincentives to the collective action that meaningful democratic politics requires.

Fake news threatens the democratic process in myriad ways but none so effectively as being aimed at influencing outcomes counter to popular will (Uscinski 2019). There are those who benefit from using fake news despite its impact on information and democracy, one might argue, precisely because of its impact on information and democracy. We should recognise that periods in which economics and politics merge have historically all been followed by popular anger, extreme politics, indiscriminate and racial violence, economic sluggishness, and a sapping of any collective energy to achieve anything civil or ambitious or necessary (such as punish the culprits). In addition, and possibly more disconcerting, is the discernible difference from previous periods in the increasing amount of fake news found in governmental information or national news outlets which 'benefits' from the speed at which fake news can travel (Lazer et al. 2018; Vosoughi, Roy, and Aral 2018). As such, fake news can be used in a manner resembling propaganda (Radnitz 2018; Garrett 2017; Oliver and Wood 2014; Weeks, Ardèvol-Abreu, and Gil de Zúñiga 2017; Oreskes and Conway 2010).

The motive for perpetuating quasi-truths, half-truths, non-truths is not particularly obscure. Wielding an emotional weapon to cloud clear thinking and objective observation is motivated in order to achieve an outcome. The political, social, and economic shifts that have taken place over the past several decades - such as more openly hostile and polarised politics, growing economic burdens on greater numbers of citizens - open up new, potentially unimagined areas for generating money. Conflict, uncertainty, and having mechanisms in place for extracting any remaining profits from a politically weak and divided country are the goal. Those who stand to profit (in the strictest sense of the word) understand this. As fake news sows discord and division, this keeps broad-based political action, such as redistribution or coordinated responses to climate change, at arm's length and undermines attempts to change the status quo. In an environment in which the strategic deployment of fake news profits political and economic incumbents, an effective 'topdown' institutional response is unlikely. 
Such a development is a fair description of the three-year process of Brexit, the recent 2016 US elections, and even the immigration issue during the refugee crisis of 2015-17 in the EU. Demobilising swaths of voters by emotional attrition and mobilising others to a reality designed to distort actually existing problems accrues power to those already in place. Thus, if and when fake news floods the newssphere, the resulting inability to have even-footed discussions benefits the political and economic incumbents.

\section{What is to be done?}

Our defenses against such deployment are weak. As the Center for Media Pluralism and Media Freedom at the European University Institute in Florence has pointed out, at present, most EU countries do not have specific requirements that ensure transparency and fair play in online campaigning. ${ }^{8}$ Attempts have been made to measure, at a minimum, the enactment/enforcement of new neutrality law(s) and active (public) efforts to confront fake news/disinformation. However, as acknowledged by the European Commission, what are national and supranational governments to do about the rise of new problems, such as the exposure of citizens to large-scale online disinformation efforts and micro-targeting of voters based on the unlawful processing of personal data?

However, there are reasons to be confident in a collective and individual response to fake news. Most news in general, including fake news, is consumed by a minority of politically active people who already have highly skewed information diets. Both conspiracy theories and fake news attract their own customers as those predisposed to them will actively search for them (Edelson et al. 2017; Clarke 2007; Uscinski, DeWitt, and Atkinson 2018; Uscinski, Klofstad, and Atkinson 2016). For an institutional response, one might propose to identify a means to regulate the Internet on impartiality, transparency, equal opportunities in media access, political advertising, and labelling political ads. At the same time, providing more information or 'facts' does not appear to have had a significant impact on the levels of political information or knowledge. Research in Political Science and Psychology has shown that providing evidence, even motivating that information with incentives, provides only occasional change and little lasting impression (see Bolsen and Druckman 2015; Lewandowsky et al. 2012; Nyhan and Reifler 2015; Prior, Sood, and Khanna 2015). More challengingly, if we are to support the idea of regulating the Internet, we require an answer to the question: who should be the arbiter of what is real and what is not? That question may be too difficult to answer and any resulting gatekeeper derived from asking this question would be too powerful.

Thus, an institutional response to fake news is likely to be ineffective and demonstrate an incomplete understanding of the problem. If this is the case, one might propose individual immunisation; that is, to cultivate individual immunisation from the intended effects of 'fake news'/disinformation through the promotion 


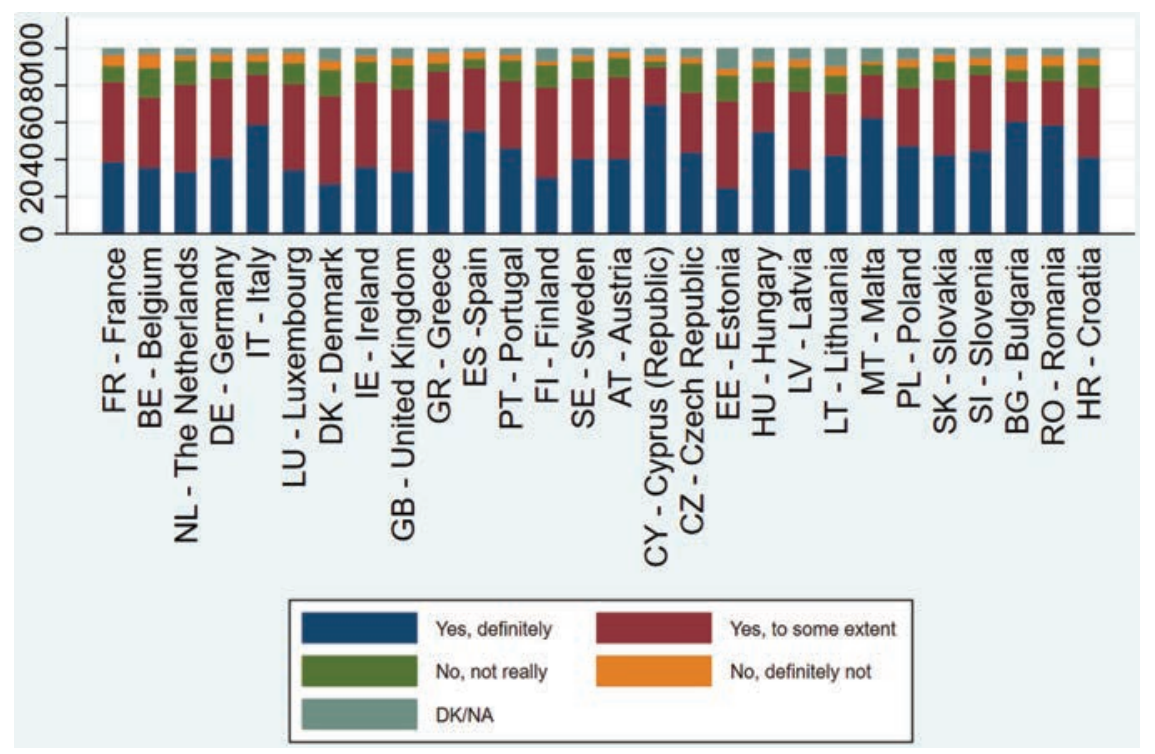

FIGURE 5.1 Is fake news a problem??

Source: Eurobarometer 464: Feb-Mar 2018.

of 'media and digital literacy' courses; raising public awareness about the existence and dangers of 'fake news'/disinformation; and building human resilience (Roozenbeek and van der Linden 2018). Which may in turn help us make better policy choices.

In the case of Europe, how do citizens of the EU see fake news? Using the question, "In your opinion, is the existence of news or information that misrepresent reality, or is even false, a problem? (Response categories: Yes, definitely; Yes, to some extent; No, not really; No, definitely not) from the Eurobarometer 464 (2018, Question 4), we can see the EU citizens' answers to this question (Figure 5.1). In every country, more than 50\% say, "Yes, Definitely" and "Yes, to some extent".

However, one disquieting aspect of the results in Figure 5.1 is that in Greece, Malta, Italy, Cyprus, Spain (almost Portugal), more than 50\% responded only 'Yes, definitely". That is, despite five response categories ranging from a strong disagreement to strong agreement, the majority responded with fake news is 'definitely' a problem. Lowering the threshold to $45 \%$ of respondents, these Southern European countries are joined by Hungary, Bulgaria, Romania, Poland, Czech Republic, Slovenia, and Slovakia. Remarkably, estimating a simple model with this question as the dependent variable,${ }^{10}$ there is very little correlation with socio-demographic or socio-economic profiles of respondents. What is more important is the regionality of these perceived issues. Southern and Eastern European countries rank lower on measures of democracy, such as civil liberties and political rights. ${ }^{11}$ Taken 
together, we can see that countries with shorter histories of democracy, less welldeveloped civil societies, and recent national economic struggles also have majorities (or solid pluralities) of citizens responding that fake news is a problem. This correlation is troubling. However, in the same survey, not only does every single EU member state country exhibit concern about fake news, but a vast majority of respondents report having seen fake news at least once a week, ${ }^{12}$ and most are somewhat to very confident that they can identify it. ${ }^{13}$ This may offer a faint positive note that not only do European citizens report that that they see a lot of fake news but rather that they think they can.

\section{Conclusion}

Fake news has exposed the disconnect between information and democracy and highlighted the importance of the relationship between feelings and information and democracy. Our normative theories of democracy require a great deal from citizens. It feels 'more correct' to say that people should be more intelligent and try to understand politics. Yet, even the amount of staggering political unsophistication previously observed in the US (Campbell et al. 1960), corresponded to a time considered by many a golden era of US politics. The use of fake news has taken advantage of the delivery system of the Internet and how it connects us to sow discord and create disunity. It exploits and amplifies our fears and concerns, appealing to how the world makes us feel rather than how it is. Yet, this strategy rests neatly on the tectonic fault lines of social, political, and economic shifts, which have been growing for the past several decades. In this way, while a challenge, it is predominantly an unfortunate covariate rather than a determinant of the problem between information and democracy.

\section{Notes}

1 While the exact quote may not have been written by Thomas Jefferson, the widely 'quoted' sentiment underpins his views on education, knowledge, and republican selfgovernance (Source: The UNESCO World Heritage Thomas Jefferson Monticello, www.monticello.org/site/research-and-collections/educated-citizenry-vital-requisiteour-survival-free-people-spurious).

$253.6 \%$ of the global population has access to the Internet. For Europe, it is $82.5 \%$ (Source: International Telecommunications Union; https://www.itu.int/en/ITU-D/Statistics/ Documents/facts/FactsFigures2019.pdf).

3 I call this the George Costanza defense: "It's not fake news if you believe it."

4 Kavanagh and Rich $(2018,4)$ : "It is worth noting that although we are calling the phenomenon "truth decay," we are not talking about "truth" in the philosophical sense ... Instead, ... the term "Truth Decay" [is] a shorthand for ... the importance of facts and fact-based analysis rather than on "truth".

5 In an interview with Michael Lewis, Steve Bannon said, "The real opposition is the media. And the way to deal with them is to flood the zone with shit." (Lewis 2018)

6 The Russian dissident and chess champion, Garry Kasparov, once commented on Soviet 'news' thusly, "the point of modern propaganda isn't only to misinform or push an agenda. It is to exhaust your critical thinking, to annihilate truth" (emphasis mine). 
7 Put differently, if a citizen of a democratic country is genuinely upset by the 'news' that 'George Soros eats Christian babies', fake news is not the number one problem for that person, nor for us.

8 Their own Digital Monitor provides an inverse media pluralism measure, the Resilience Index, defined by the availability of and access to informational options. The digital monitor identifies macro- and individual-level measures that distinguish the availability of and access to informational options of the Internet by nations.

9 Data sourced from Eurobarometer Flash Survey 464, European Commission, Brussels (2018) Flash Eurobarometer 464 (Fake News and Disinformation Online). TNS opinion, Brussels [producer]. GESIS Data Archive, Cologne. ZA6934 Data file Version 1.0.0, https://doi.org/10.4232/1.13019

10 The Ordinary Least Squares (OLS) model is not shown for space but is available from the author.

11 Freedom House: Freedom in the Worlds. Source: https://freedomhouse.org/reports.

12 (Q3) "How often do you come across news or information that you believe misrepresent reality or is even false?" Response categories: Every day or almost every day, At least once a week, Several times a month, Seldom or Never.

13 (Q2): "How confident or not are you that you are able to identify news or information that misrepresent reality or is even false?" Response categories:Very confident, Somewhat confident, Not very confident, Not at all confident.

\section{References}

Achen, C.H., L.M. Bartels (2016) Democracy for Realists: Why Elections Do Not Produce Responsive Government, Princeton, NJ: Princeton University Press.

Allcott, H., M. Gentzkow (2017) 'Social media and fake news in the 2016 election', Joumal of Economic Perspectives 31: 211-36.

Berinsky, A. (2012) 'Rumors, truths, and reality: A study of political misinformation', MIT, http://web.mit.edu/berinsky/www/files/rumor.pdf.

Bolsen, T., J.N. Druckman (2015) 'Counteracting the politicization of science', Political Communication 65(5): 745-69.

Butler, D.H.E., D. E. Stokes (1969) Political Change in Britain: Forces Shaping Electoral Choice, New York: St. Martin's Press.

Campbell, A., P.E. Converse, W.E. Miller, D.E. Stokes (1960) The American Voter, Chicago: University of Chicago Press.

Clarke, S. (2007) 'Conspiracy theories and the internet: Controlled demolition and arrested development', Episteme 4: 167-80.

Dagnall, N., K. Drinkwater, A. Parker, A. Denovan, M. Parton (2015) 'Conspiracy theory and cognitive style: A worldview', Frontiers in Psychology 6: 206.

Dahl, R.A. (1989) Democracy and Its Critics, New Haven: Yale University Press.

Dahlgren P. (2000) 'The Internet and the democratization of civic culture', Political Communication, 31(3): 329-84.

Douglas, K.M., J.E. Uscinski, R.M. Sutton, A. Cichocka, T. Nefes, C.S. Ang, F. Deravi (2019) "Understanding conspiracy theories" Political Psychology, 40: 3-35. doi:10.1111/ pops. 12568 .

Downs, A. (1957) An Economic Theory of Democracy. London: Harper Collins.

Druckman, J. N. (2012) “The politics of motivation', Critical Review 24(2): 199-216.

Druckman, J.N., E. Peterson, R. Slothuus (2013) 'How elite partisan polarization affects public opinion formation', American Political Science Review 107(1): 57-79.

Edelson, J., A. Alduncin, C. Krewson, J. A. Sieja, J.E. Uscinski (2017) 'The effect of conspiratorial thinking and motivated reasoning on belief in election fraud', Political Research Quarterly 70: 933-46. 
Flynn, D.J., B. Nyhan, J. Reifler (2017) "The nature and origins of misperceptions: understanding false and unsupported beliefs about politics", Political Psychology 38: 127-50.

Frank, T. (2004) What's the Matter with Kansas? How Conservatives Won the Heart of America, New York: Metropolitan Books.

Freeman, D. (2007) 'Suspicious minds: The psychology of persecutory delusions', Clinical Psychology Review 27: 425-57.

Garrett, R.K. (2017) 'The "echo chamber" distraction: Disinformation campaigns are the problem, not audience fragmentation', Joumal of Applied Research in Memory and Cognition 6: 370-76.

Gil de Zúñiga, H., N. Jung, S. Valenzuela (2012) 'Social media use for news and individuals' social capital, civic engagement and political participation, Joumal of Computer-Mediated Communication 17(3): 319-36.

Hart, P.S., E.C. Nisbet (2012) 'Boomerang effects in science communication: How motivated reasoning and identity cues amplify opinion polarization about climate mitigation policies', Communication Research 39(6): 701-23, doi 10.1177/0093650211416646.

Kahan, D. M. (2016) 'The politically motivated reasoning paradigm, part 1: What politically motivated reasoning is and how to measure it', Emerging Trends in the Social and Behavioral Sciences: An Interdisciplinary, Searchable, and Linkable Resource, 1-16.

Karp, J. A., A. Nai, P. Norris (2018) "Dial "F" for fraud: Explaining citizens suspicions about elections', Electoral Studies 53: 11-19.

Kavanagh, J., M. D. Rich (2018) Truth Decay: An Initial Exploration of the Diminishing Role of Facts and Analysis in American Public Life, Santa Monica, CA: RAND Corporation.

Key, V.O. Jr. (1961) Public Opinion and American Democracy, New York: Alfred A. Knopf.

Kunda, Z. (1990) 'The Case for motivated reasoning', Psychological Bulletin 108: 480-98, doi: $10.1037 / 0033-2909.108 .3 .480$.

Lau, R., D.J. Andersen, D.P. Redlawsk (2008) 'An exploration of correct voting in recent US presidential elections', American Joumal of Political Science 52 (2): 395-411.

Lazer, D. M.J., M. A. Baum, Y. Benkler, A.J. Berinsky, K. M. Greenhill, F. Menczer (2018) "The science of fake news', Science 359: 1094-96.

Lewandowsky, S., K.H.E. Ullrich, J. Cook (2017) 'Beyond misinformation: Understanding and coping with the 'post-truth' era', Joumal of Applied Research in Memory and Cognition 6: 353-69.

Lewandowsky, S., K. H. E. Ullrich, C. Seifert, N. Schwarz, J. Cook (2012) 'Misinformation and its correction', Psychological Science in the Public Interest 13(3): 106-31.

Lewis, M. (2018) 'Has anyone seen the president?', Bloomberg, 9 February 2018, www. bloomberg.com/opinion/articles/2018-02-09/has-anyone-seen-the-president (last consulted 12 January 2020).

Lodge, M., C. Taber (2000) "Three steps toward a theory of motivated political reasoning', in: A. Lupia, M.D. McCubbins, S.L. Popkin (eds) Elements of Reason: Cognition, Choice, and the Bounds of Rationality, Cambridge: Cambridge University Press, 183-213.

Lodge, M., K.M. McGraw (eds) (1995) Political Judgment: Structure and Process, Michigan: University of Michigan Press.

Lupia, A., M.D. McCubbins (1998) The Democratic Dilemma: Can Citizens Learn What They Need to Know? Cambridge: Cambridge University Press.

Lupia, A., M.D. McCubbins, S. L. Popkin (eds) (2000) Elements of Reason: Cognition, Choice, and the Bounds of Rationality, Cambridge: Cambridge University Press.

Luskin, R.C. (1987) 'Measuring political sophistication', American Joumal of Political Science, 856-99.

Nisbet, E. C., E. Stoycheff, K.E. Pearce (2012) 'Internet use and democratic demands: A multinational, multilevel model of internet use and citizen attitudes about democracy', Joumal of Communication 62(2): 249-65. 
Nyhan, B., J. Reifler (2015) "The effect of fact-checking on elites: A field experiment on us state legislators", American Journal of Political Science 59(3): 628-40.

Oliver, E., T. Wood (2014) "Conspiracy theories and the paranoid style(s) of mass opinion", American Journal of Political Science 58: 952-66.

Olson, M. (1965) The Logic of Collective Action: Public Goods and the Theory of Groups, Cambridge, MA: Harvard University Press.

Oreskes, N., E.M. Conway (2010) Merchants of Doubt, London: Bloomsbury Publishing.

Page, B.I., R. Y. Shapiro (1992) The Rational Public: Fifty Years of Trends in American Policy Preferences, Chicago: University of Chicago Press.

Prior, M. (2007) Post-Broadcast Democracy: How Media Choice Increases Inequality in Political Involvement and Polarizes Elections, Cambridge: Cambridge University Press.

Prior, M., G. Sood, K. Khanna (2015) "You cannot be serious: The impact of accuracy incentives on partisan bias in reports of economic perceptions", Quarterly Journal of Political Science 10: 489-518.

Przeworski, A., H. Teune (1970) The Logic of Comparative Social Inquiry, Hoboken, NJ: Wiley.

Radnitz, S. (2018) 'Why the powerful (in weak states) prefer conspiracy theories', in: J.E. Uscinski (ed.) Conspiracy Theories and the People Who Believe Them, New York: Oxford University Press, 347-59.

Redlawsk, D.P. (2002) 'Hot cognition or cool consideration? Testing the effects of motivated reasoning on political decision making', Joumal of Politics 64(4): 1021-44.

Roozenbeek, J., S. van der Linden (2018) 'The fake news game: actively inoculating against the risk of misinformation', Joumal of Risk Research 1-11, doi: $10.1080 / 13669877.2018 .1443491$.

Shirky, C. (2011) 'the political power of social media: Technology, the public sphere, and political change', Foreign Affairs 90(1): 28-41.

Sniderman, P.M. (2000) 'Taking sides: A fixed choice theory of political reasoning', in: A. Lupia, M.D. McCubbins, S. L. Popkin (eds) Elements of Reason: Cognition, Choice, and the Bounds of Rationality, Cambridge: Cambridge University Press, 67-84.

Sniderman, P.M., R.A. Brody, P.E. Tetlock (1991) Reasoning and Choice: Explorations in Political Psychology, Cambridge: Cambridge University Press.

Ståll, T., J-W van Prooijen (2018) 'Epistemic rationality: Skepticism toward unfounded beliefs requires sufficient cognitive ability and motivation to be rational', Personality and Individual Differences 122: 155-63.

Suhay, E., J. N. Druckman, P. W. Kraft, M. Lodge, C. S. Taber (2015) 'Why people don't trust the evidence', The Annals of the American Academy of Political and Social Science 658(1): 121-33.

Taber, C., M. Lodge (2006) 'Motivated skepticism in the evaluation of political beliefs', American Joumal of Political Science 50(3): 755-69.

Uscinski, J.E. (ed.) (2018) Conspiracy Theories and the People Who Believe Them, New York: Oxford University Press.

Uscinski, J.E. (2020) 'Conspiracy theories', in: E. Suhay, B. Grofman, A.H. Trechsel (eds) The Oxford Handbook of Electoral Persuasion, Oxford: Oxford University Press, 523-53.

Uscinski, J.E., C. Klofstad, M. Atkinson (2016) 'Why do people believe in conspiracy theories? The role of informational cues and predispositions', Political Research Quarterly 69: $57-71$.

Uscinski, J.E., D. DeWitt, M. Atkinson (2018) "A web of conspiracy? Internet and conspiracy theory", in: A. Dyrendal, D. Robinson, E. Asprem (eds), The Brill Handbook of Conspiracy Theory and Contemporary Religion, Boston, MA: Brill.

Valenzuela, S., N. Park, K.F. Kee (2009) 'Is there social capital in a social network site?: Facebook use and college students' life satisfaction, trust, and participation', Joumal of Computer-Mediated Communication 14(4): 875-901. 
Vosoughi, S., D. Roy, S. Aral (2018) 'The spread of true and false news online', Science 359: 1146-51.

Walker, J. (2018) 'What we mean when we say "conspiracy theory"” in: J.E. Uscinski (ed.), Conspiracy Theories and the People Who Believe Them, New York: Oxford University Press, 53-61.

Ward, S., R. Gibson, W. Lusoli (2003) 'Online participation and mobilisation in Britain: Hype, hope and reality’, Parliamentary Affairs 56: 652-68.

Weber, L.M., A. Loumakis, J. Bergman (2003) 'Who participates and why? An analysis of citizens on the internet and the mass public', Social Science Computer Review 21(1): 26-42.

Weeks, B.E., A. Ardèvol-Abreu, H. Gil de Zúñiga (2017) 'Online influence? Social media use, opinion leadership, and political persuasion', Intemational Journal of Public Opinion Research 29: 214-39.

Zaller, J. (1992) The Nature and Origins of Mass Opinion, Cambridge: Cambridge University Press.

Zhang, W., T.J. Johnson, T. Seltzer, S.L. Bichard (2010) 'The revolution will be networked: The influence of social networking sites on political attitudes and behavior', Social Science Computer Review 28(1): 75-92. 